\title{
Impactos do Programa Internacional de Avaliação de Estudantes (Pisa) sobre a qualidade da educação
}

\author{
Solange Santiago Ferreira
}

\author{
ORTIGÃO, Maria Isabel Ramalho (Org.). Políticas de \\ avaliação, currículo e qualidade: diálogos sobre o Pisa. \\ Curitiba: CRV, 2018. 268 p.
}

A coletânea Políticas de avaliação, currículo e qualidade: diálogos sobre o Pisa, organizada por Maria Isabel R. Ortigão (2018) é resultado de muitos diálogos e investigações sobre o Programa Internacional de Avaliação de Estudantes (Programme for International Student Assessment - Pisa) como uma das vertentes para se pensar a educação. Algumas dessas investigações foram desenvolvidas pelo grupo Currículo: Sujeitos, Conhecimento e Cultura, no Programa de Pós-Graduação em Educação (ProPed) da Universidade do Estado do Rio de Janeiro (Uerj), outras por grupos de pesquisa com os quais o da Uerj mantém interlocução. O livro reúne textos que contribuem com vários olhares sobre o Pisa, propiciando reflexões acerca de políticas de avaliação e currículo, qualidade das escolas, conhecimento/letramento científico e formação docente.

Os 13 capítulos trazem diversas abordagens teórico-metodológicas, ora levantando questões sobre os modelos homogeneizadores, os impactos sobre a qualidade educacional, as políticas públicas no campo, ora analisando os resultados do desempenho dos estudantes, mediante gráficos, formas de aplicação e fundamentos, como também seus reflexos nos sistemas educativos.

O Pisa é conduzido pela Organização para a Cooperação e Desenvolvimento Econômico (OCDE) e voltado à comparação de performances relacionadas aos conhecimentos de jovens de 15 anos de idade no que tange à sua compreensão leitora e à competência matemática e científica. O conjunto de instrumentos de avaliação é realizado em países cujas características e realidades socioeconômicas e culturais são diferentes. 
Ressaltando o último aspecto, Ortigão afirma, na Apresentação, que, "de modo geral, as evidências de melhorias nos resultados são modestas e, em alguns casos, pouco significativas" (p. 11); daí emergem críticas considerando que os resultados não são analisados em relação à diversidade inerente a cada país participante, ao contrário, tomam-se por base os países desenvolvidos. Os questionamentos, segundo a autora, estendem-se às tentativas de imposição de um só modelo de formação para os jovens, cujo alicerce se pauta no sujeito ideal imerso no mundo globalizado, em que prevalece a ideia de um "mundo melhor" em detrimento das diferenças socioeconômicas e culturais.

A organizadora da obra, Maria Isabel Ramalho Ortigão, doutora em Educação pela Pontifícia Universidade Católica do Rio de Janeiro (PUC-Rio), é professora adjunta da Uerj e do ProPed, pesquisadora Jovem Cientista do Nosso Estado da Fundação Carlos Chagas Filho de Amparo à Pesquisa do Estado do Rio de Janeiro (Faperj) e Procientista Faperj/Uerj, coordenadora do grupo de pesquisa Políticas de Avaliação, Desigualdades e Educação Matemática e do Grupo de Trabalho Avaliação e Educação Matemática, da Sociedade Brasileira de Educação Matemática (Sbem).

No livro estão reunidos pesquisadores de quatro países - Brasil, Espanha, México e Portugal -, com o objetivo de socializar resultados de pesquisa ou ensaios teóricos decorrentes de reflexão sobre o Pisa. Serão apresentados, a seguir, os principais diálogos estabelecidos pelos autores participantes da obra.

O primeiro, de Ángel Diaz-Barriga, pesquisador mexicano do Instituto de Investigadores sobre La Universidad y La Educación, na Universidad Nacional Autónoma de México (Unam), intitula-se "A Prova Pisa: idealização, cidadania global, imposição cultural e ausência de impacto pedagógico didático" e desenvolve-se com base em três dimensões: a política, a técnica e a pedagógico-didática, visto que com uma tripla visão sobre o Programa poderia "dimensionar suas possibilidades e limitações" (p. 19), apontando entre estas a "modelização das aprendizagens, dos estudantes como pessoas" (p. 19), pois não leva em conta as diferenças culturais, sociais e econômicas de cada país-membro. Diaz-Barriga afirma que o Pisa propicia altos custos aos países e, do ponto de vista técnico, é um exame que inovou na construção da teoria do teste, mas a difusão dos resultados dos alunos pela via de gráficos favorece a comparação entre os países, colocando-os em um ranking cuja competição acirrada dos gestores desconsidera o que para o autor é essencial: a formulação de políticas que transformem estruturalmente a cultura escolar dos sistemas educacionais, alterando os planos de estudo e as práticas docentes na formação de professores e também os planos de estudo da educação básica. O autor defende que, dessa forma, seriam dadas as condições de aplicação de distintos saberes de diferentes disciplinas. Isso propiciaria a resolução de problemas, promovendo uma "docência coletiva" e estabelecendo outros mecanismos de funcionamento escolar.

No segundo capítulo, "Para compreender o desempenho dos alunos portugueses no Pisa (2000-2015)", Domingues Fernandes, professor da Universidade de Lisboa, e Conceição Gonçalves, técnica do Ministério da Educação de Portugal, afirmam que o país tem tido progressos relevantes nos ciclos do Programa e 
subdividem a análise em três eixos: o enquadramento conceitual, realizando uma revisão de literatura que constitui o referencial teórico do trabalho; o desempenho dos alunos portugueses no Pisa, apresentando alguns dados que evidenciam a melhoria dos resultados nas diferentes edições do Programa; e, por fim, as políticas públicas de educação em Portugal (1986-2015), analisando a Lei de Bases no Sistema Educativo (LBSE) e afirmando que alguns programas-chave culminaram na criação de políticas públicas de educação no país desde 1986.

Os autores concluem que, por envolverem as estruturas da educação, a formação continuada de professores em regime de colaboração com o ensino superior e a valorização profissional dos docentes, os programas concebidos em Portugal favorecem o melhor desempenho dos alunos no Pisa, visto que os debates são preconizados pela participação democrática e avaliação daqueles programas e, ainda, pela oferta de educação diversificada e flexibilidade nos currículos, que são revistos e reajustados periodicamente. As mudanças em decorrência das discussões são inseridas na agenda da LBSE.

No terceiro capítulo, "Transformar a avaliação através do Pisa: o Projeto GapPisa", os professores Esperanza Mejas Macias e Carles Monero Font, vinculados à Universidade Autônoma de Barcelona (Espanha), em consenso educacional sobre a necessidade de ensinar e avaliar competências, que corroboram a construção de uma cidadania reflexiva e crítica, compartilham a experiência de um projeto de pesquisa e intervenção de formação continuada para docentes da educação infantil, primária e secundária e tem como foco a concepção e validação de instrumentos de avaliação por competências, mediante a modificação das provas que os docentes utilizam. O instrumento formulado resultou no Guia GapPisa, que tem fundamentos nas bases psicoeducacionais das provas do Pisa, buscando um caráter mais formativo e inclusivo, no sentido de transformar a avaliação num processo que se estenda a toda equipe docente.

Em "Métodos e conhecimentos científicos como desafios para a educação", Rosa Maria Corrêa das Neves, pesquisadora da Escola Politécnica de Saúde Joaquim Venâncio (EPSJV), unidade técnico-científica da Fundação Oswaldo Cruz (Fiocruz), e Siomara Borba, professora do Proped/Uerj, envolvidas profissionalmente com educação e ciências, buscam demonstrar que a transformação da avaliação não consiste em uma atividade pontual, mas num processo estendido aos docentes, integrando-se à prática pedagógica deles. Assim, dão ênfase à compreensão teórica sobre o que é ciência, trazendo à tona questões que envolvem cientificidade e produção do conhecimento. Não discorrem especificamente sobre o Pisa, entretanto, trazem contribuições no sentido de se entender o conhecimento científico ou o letramento científico, propostos pelo Programa, no qual os estudantes se submetem a testes de Leitura, Matemática e Ciências.

O quinto capítulo, "O Pisa como estratégia política neoliberal produtora de performatividade na educação", de Antonia Alves Pereira Silva, professora da Universidade do Estado do Piauí (Uespi) e doutoranda do ProPed/Uerj, tem como objetivo "discutir que o Pisa, como ação da OCDE, está comprometido com uma concepção neoliberal de educação que, utilizando tecnologias políticas, colabora para 
criação de uma cultura performativa na educação via mudanças na cultura escolar" (p. 109). Segundo a autora, a lógica neoliberal tem perpassado pelo campo educacional, aproximando-se da lógica do mercado por meio de gerenciamento, regulação e competitividade, e o Pisa estaria favorecendo tal lógica. Tendo como referenciais Stephen Ball e Popkewitz, a autora contribui com reflexões sobre a avaliação em larga escala, a qual estaria voltada para formar sujeitos em sintonia com a lógica de mercado. Ao mesmo tempo, avalia que o Pisa deveria direcionar seus objetivos para a resolução dos problemas educacionais, em vez de ter uma função métrica, classificatória, que propõe "soluções globais aos problemas educacionais locais", assumindo a posição de regulador das políticas de educação dos países (p. 123) e atendendo, dessa forma, aos discursos neoliberais dos agentes educacionais locais. A autora destaca a resistência à performatividade neoliberal como aspecto favorecedor da compreensão da atuação das políticas no âmbito da escola, de modo a produzir outros sentidos para a política neoliberal (p. 123).

No sexto capítulo, "Repetência e equidade em Educação no Brasil: reflexões a partir do Pisa 2015", Daniel Abud Seabra Matos e Luciano Campos da Silva, professores titular e associado, respectivamente, da Universidade Federal de Ouro Preto, e Maria Eugênia Ferrão, professora da Universidade da Beira Interior (UBI) e investigadora da Universidade de Lisboa, com apoio nos resultados do Pisa 2015 e mediante uma abordagem quantitativa, realizam uma análise comparativa entre as unidades da Federação e as regiões brasileiras no quesito repetência. Este é discutido com base na situação do aluno e sua trajetória escolar e na proporção de repetentes das escolas brasileiras. Os dados mostram a relação entre repetência, nível socioeconômico e sexo.

Pela análise dos resultados, é possível compreender de que forma algumas instituições concentram maior número de repetência. Os dados da pesquisa sugerem a existência de um processo de segregação escolar que "tende a concentrar no interior de determinadas instituições estudantes com maior histórico de fracasso escolar" (p. 136). Isso se constituiria alvo de estudos mais aprofundados para que se promovessem discussões profícuas acerca da qualidade e equidade da educação. O Pisa, nesse sentido, não atinge o propósito, considerando que a avaliação é por amostragem.

No sétimo capítulo, "Pisa 2012: uma análise dos itens da Matemática", Maria Isabel R. Ortigão, professora do ProPed/Uerj, investiga o comportamento diferencial dos itens de matemática aplicados nessa edição do Programa, comparando os resultados entre estudantes brasileiros e portugueses. O trabalho da autora teve como objetivo verificar se os itens de matemática aplicados na edição de 2012 do Pisa apresentavam Funcionamento Diferencial dos Itens (DIF), expressão que se refere a detectar aqueles "cuja probabilidade de acertos difere entre grupos distintos de uma população cujas pessoas possuem o mesmo nível de habilidade na variável medida" (p. 142). A análise descritiva das características daqueles que apresentaram DIF revelou a existência de distintas habilidades cognitivas entre os grupos de estudantes considerados.

Ortigão ressalta que as características de cada país exercem influência na organização de seu sistema educacional, na forma como os currículos são elaborados 
e nos critérios de seleção dos conteúdos e enfatiza que os desempenhos escolares sofrem influência das diferenças individuais, socioeconômicas e culturais dos estudantes. Segundo a autora, a presença do comportamento diferencial pode indicar competências distintas dos alunos avaliados nos diversos países-membros e a possibilidade de conhecer as características elencadas por meio dos itens que favorecem determinados grupos e a percepção de padrões específicos, muitas vezes, não são observadas pelos especialistas. Assim, o DIF pode favorecer a construção de outras formas de colaborar para o aprendizado dos alunos na medida em que há identificação das diferenças existentes, trazendo contribuições substanciais para a avaliação educacional.

No oitavo capítulo, "Letramento científico no Pisa", Adriele Ferreira Muri, professora da Universidade Federal de Rondônia (Unir), discute o conceito de letramento científico em um estudo de caráter teórico-metodológico, destacando a forma do conceito apresentada pelo Pisa e pela OCDE e mapeia os diferentes sentidos atribuídos a ele com a intenção de fundamentar a sua análise em documentos oficiais do Programa. A autora considera que o letramento científico no Pisa se associa à capacidade de ir além da simples aquisição de conhecimentos, pois inclui atitudes, crenças e interesses que influenciam decisões e ações em uma perspectiva pessoal, social e cultural. O conceito de letramento científico, para Muri, favorece o desenvolvimento da capacidade de análise, raciocínio e reflexão sobre conhecimentos e experiências por parte dos estudantes.

No nono capítulo, "A avaliação em Ciências no Pisa", Talita Vidal Pereira, professora do ProPed/Uerj e do Programa de Pós-Graduação em Educação, Cultura e Comunicação (PPGECC), e Renata Leite de Oliveira, professora da rede municipal de Nova Iguaçu, estado do Rio de Janeiro, e doutoranda do ProPed/Uerj, defendem a importância do ensino de Ciências para a formação cidadã dos sujeitos. Assim, faz-se necessário problematizar a avaliação em larga escala no sentido de verificar a garantia da qualidade da educação expressa por meio de aprendizagens de certos conteúdos passíveis de serem aferidos em testes padronizados como o Pisa. Este se revela na lógica do controle, frequentemente implementado em tal tipo de avaliação, e parte do pressuposto de que as culturas são iguais, em que prevalece o senso comum, gerando mais processos excludentes. A percepção das disputas em torno dos significados de ciência, de conhecimento, de educação, de ensino e de currículo pode determinar outro caminhar para pesquisadores e educadores.

No décimo capítulo, "Itens de Ciências no Pisa: interpretações", Marcelo S. O. Massunga, professor associado da Universidade Estadual do Norte Fluminense Darcy Ribeiro (Uenf), Gustavo Rubini, técnico em assuntos educacionais e doutorando do Programa de Pós-Graduação em Ensino da Universidade Federal do Rio de Janeiro (UFRJ), e Marta F. Barroso, professora desta universidade, apresentam uma interpretação empírica do fato de que mais de $50 \%$ dos estudantes brasileiros estão abaixo do nível 2 na escala de proficiência em Ciências no Pisa. Com base na experiência, destacam a importância de discutir a formação de professores de forma mais aprimorada, no sentido da compreensão do termo "contextualização" e se esse estaria impactando os resultados observados.

No décimo primeiro capítulo, Antonio Fernando Zucula, professor da Academia de Ciências Policiais de Moçambique (Acipol), Carlos Augusto Aguiar Junior, professor 
do Colégio de Aplicação da Universidade Federal Fluminense (UFF), e Guilherme Pereira Stribel, todos doutorandos no ProPed/Uerj, apresentam o "Desempenho dos estudantes brasileiros em Matemática no Pisa em 2012 e 2015". Os autores concluem que não houve avanços em relação ao nível de proficiência e apontam a necessidade de articulação entre os dados da proficiência e os resultados dos questionários contextuais do professor e da escola. Assim, seria possível repensar o processo de ensino-aprendizagem, uma vez que a avaliação dos conhecimentos matemáticos ocorre com base na concepção de letramento matemático, e a escola poderia traçar outros caminhos mais profícuos considerando os dados coletados.

O texto de Maria José Costa dos Santos, professora da Universidade Federal do Ceará, intitulado "Pisa 2015: análises e reflexões sobre o desempenho dos estudantes cearenses", é um estudo sobre a área de Matemática, com base na leitura de documentos da OCDE. A autora ressalta que o desempenho dos estudantes cearenses está acima da média nacional, destaca a importância de atentar para a inserção das organizações privadas nas discussões sobre qualidade do ensino e recomenda um estudo sobre a evolução educacional no Ceará e que as políticas implementadas e os resultados obtidos no estado sirvam de inspiração para outras regiões do País.

No último capítulo, "Dependência administrativa das escolas, desigualdade de oportunidades de aprendizagem e desempenho em Matemática no Pisa 2012", Glauco da Silva Aguiar, professor do mestrado profissional da Fundação Cesgranrio, discute sobre a necessidade de políticas públicas como forma de reduzir as desigualdades educacionais em sua origem. O autor explora o conceito de "oportunidade de aprendizagem", que, segundo ele, se baseia "no senso comum de que o tempo que um estudante investe aprendendo alguma coisa está relacionado com o que aprende" (p. 245). Foram aplicados questionários aos estudantes e à escola. Com base nos dados, são apresentadas evidências de desigualdades sociais, econômicas e culturais. O autor ressalta, no âmbito das políticas públicas, fatores essenciais para a melhoria do desempenho dos estudantes e a superação de problemas relacionados à aprendizagem de Matemática, tais como: a necessidade da qualificação profissional, que inclui a formação inicial e continuada; a melhoria nas condições de trabalho do professor; e a valorização profissional deste. Tal conjunto de ações favoreceria a equidade nas escolas.

Solange Santiago Ferreira, doutora em Educação pela Universidade Federal Fluminense (UFF) e pesquisadora do Núcleo de Estudos e Pesquisas em Gestão e Políticas Públicas em Educação (Nugeppe) dessa universidade, é professora da Fundação Municipal de Educação de Niterói (FME), onde também é coordenadora do Núcleo de Estágio (Nest).

solsantiago@gmail.com

Recebido em 5 de agosto de 2020

Aprovado em 23 de setembro de 2020 